\title{
Interprofessional Collaboration and Burnout Nurses in Hospital
}

\author{
Rosiana Nur Imallah'1, Yuni Kurniasih ${ }^{1}$ \\ 1 Fakultas Ilmu Kesehatan, Universitas 'Aisyiyah Yogyakarta
}

\section{Article Info}

Article History:
Submitted: Dec $10^{\text {th }}, 2020$
Accepted: Jan $10^{\text {th }}, 2021$
Published: Feb $13^{\text {th }}, 2021$
Keywords:
Burnout; Interprofessional
Collaboration; Nurse

Article History:

Submitted: Dec $10^{\text {th }}, 2020$

Accepted: Jan $10^{\text {th }}, 2021$

Published: Feb 13 ${ }^{\text {th }}, 2021$

Keywords:

Collaboration; Nurse

\begin{abstract}
The demand safe for nursing services, effective nursing services, excellent service, high standard of clinical services, causes nurses to be in a state of prolonged stress. The prolonged stress experienced by nurses will result in burnout which will directly impact the quality of care and quality of nursing services performed. if this is allowed to continue it will have an impact on the future of the hospital. This study aimed to know the relationship between interprofessional collaboration with the incidence of burnout in the hospital. This study used a correlational design with a cross-sectional approach to time. The population in this study were nurses in IGD, ICU, and ICCU. Interprofessional collaboration had no relationship with nurse burnout ( $p>0.05$ ). The results of the analysis showed that nurses experienced burnout because it was influenced by other factors such as work environment, workload and work stress. Further analysis from the researcher shows that good interprofessional collaboration is needed in improving the performance of nurses but it is not the only factor that can affect nurses experiencing burnout.
\end{abstract}

\section{PENDAHULUAN}

Rumah sakit merupakan tempat untuk memberikan pelayanan kesehatan yang didalamnya terdiri dari berbagai profesi yang terlibat yaitu tenaga medis, tenaga psikologis klinis, tenaga keperawatan, tenaga kebidanan, tenaga kefarmasian, tenaga gizi, tenaga keterapian fisik, tenaga keteknisian medis dan teknik biomedika [1].Proses pelayanan di Rumah Sakit membutuhkan hubungan kerjasama yang profesional (interprofesional collaboration) antara berbagai profesi tersebut untuk menghindari terjadinya eror atau kejadian tidak diinginkan (KTD) yang mengancam kesehatan pasien dan tenaga Kesehatan [2].

Interprofessional collaboration merupakan bentuk kerjasama berbagai profesi kesehatan dengan pasien, keluarga dan komunitas untuk menyediakan pelayanan komprehensif dan berkualitas [3]. Kolaborasi interprofesi yang dilakukan dengan baik akan membuat keputusan asuhan atau pemecahan masalah menjadi lebih efektif dan bermanfaat bagi semua yang terlibat [4]. Disamping itu adanya kolaborasi akan dapat menurunkan komplikasi, konflik diantara tim kesehatan dan menurunkan kematian. Hal ini sangat

\footnotetext{
Corresponding author:

Rosiana Nur Imallah

rosiana@unisayogya.ac.id

Media Keperawatan Indonesia, Vol 4 No 1, February 2021

e-ISSN: 2615-1669

ISSN: 2722-2802

DOI: $\underline{10.26714 / \mathrm{mki} .4 .1 .2021 .56-61}$
} 
memperkuat alasan bahwa praktik kolaborasi sangat penting dalam proses pemberian layanan kesehatan di rumah sakit. Salah satu yang berperan dalam Interprofessional collaboration adalah perawat.

Perawat merupakan komponen penting di rumah sakit, karena perawat mempunyai interaksi tinggi dengan pasien dan keluarga dibandingkan dengan tenaga kesehatan lain [5]. Dalam menjalankan peran dan fungsinya perawat dituntut untuk dapat memberikan pelayanan keperawatan yang aman, efektif serta adanya standart pelayanan klinik tinggi menyebabkan perawat sering merasakan stres kerja [6].

Hasil survey yang dilakukan oleh American National for Occupational Health (ANAOH) kejadian stres kerja perawat berada di urutan pertama pada empat puluh kasus stress pada pekerja [5]. Stres kerja yang terjadi secara terus menerus akan dapat menimbulkan dampak jangka panjang seperti kejenuhan kerja atau pada saat ini sering disebut dengan istilah burnout. Gambaran burnout dapat dilihat dari tiga dimensi yaitu kelelahan emosional, depresional dan penurnan prestasi pribadi yang sering disebut dengan "sindrom burnout" [7]. Apabila sindrom burnout banyak dijumpai berarti kurangnya perhatian dari berbagai pihak terhadap profesi perawat dan apabila semakin banyak maka semakin rendah kualitas pelayanan yang diberikan [8].

Penelitian tentang Interprofessional collaboration terhadap kejadian burnout perawat di RS PKU Muhammadiyah Gamping belum pernah dilakukan sebelumnya. Ditemukannya sindrom burnout pada perawat di ruang perawatan kritis dan gawat darurat menjadi alasan penting kenapa penelitian harus dilakukan. Selain itu pelaksanaan pelayanan kesehatan di ruang kritis dan gawat darurat sangat membutuhkan interprofesional collaboration.
Penelitian ini bertujuan untuk untuk mengetahui interprofessional collaboration, burnout perawat dan mengetahui hubungan interprofessional collaboration dengan burnout perawat di RS PKU Muhammadiyah Gamping.

\section{METODE}

Penelitian ini menggunakan desain korelasional dengan pendekatan waktu cross-sectional [6]. Tujuan dari metode ini agar diperoleh data yang lengkap dalam waktu yang relatif cepat [9].Penelitian ini menghubungkan antara Interprofesional Collaboration dengan Burnout perawat. Penelitian ini dilakukan di RS PKU Muhammadiyah Gamping pada bulan Oktober-November 2020. Populasi dalam penelitian ini adalah perawat pelaksana di ruang perawatan kritis dan gawat darurat di rumah sakit PKU Muhammadiyah Gamping. Teknik pengambilan sampel dengan teknik total sampel yaitu sebanyak 51 perawat. Kriteria inklusi yaitu perawat pelaksana dan bersedia menjadi responden. Alat ukur yang digunakan dalam penelitian ini adalah kuesioner Interprofesional Collaboration yang terdiri dari 44 item pertanyaan meliputi kemitraan, kerjasama, koordinasi dan pengambilan keputusan bersama dan kuesioner Maslach Burnout Inventory (MBI) dengan 22 item pertanyaan meliputi kelelahan emosional, depersonalisasi, dan rendahnya prestasi pribadi. Pengambilan data penelitian dilaksanakan setelah lolos ethical clearance (No. 1343/KEP-UNISA/IX/2020) dan mendapatkan surat izin penelitian dari RS. Peneliti menjelaskan terlebih dahulu maksud dan tujuan penelitian kepada responden, jika responden bersedia diminta mengisi informed concern dan kuesioner dalam bentuk google form secara lengkap. Identititas responden diberi inisial dan hanya peneliti yang dapat melihat rekapan data hasil penelitian yang sudah diisi responden. Analisis data penelitian menggunakan pearson correlation. 


\section{HASIL}

Sampel dalam penelitian ini berjumlah 51 responden, dengan komposisi responden perempuan lebih banyak dari pada responden laki-laki yaitu 64,7\%. Usia responden terbanyak yaitu 25-35 tahun $(82,4 \%)$. Lama kerja terbanyak yaitu 1-5 tahun (52,9\%). Pendidikan responden terbanyak yaitu Ners ( 43,1\%). Hasil dari penelitian ini menunjukkan tidak ada hubungan antara Interprofessional Colaboration dan Burnout perawat ( $p$ $>0,05)$. Hasil penelitian dapat dilihat pada tabel 1 .

Hasil penelitian menunjukkan bahwa dari 51 responden, Interprofessional Collaboration dalam kategori tinggi (mean 4,35 ) dan burnout perawat dalam kategori sedang (mean 2,05). Hasil uji statistik diperoleh nilai $\mathrm{p}>0,05$ maka dapat disimpulkan bahwa tidak terdapat hubungan antara interprofesional Collaboration dengan Burnout Perawat. Nilai koefesien korelasi hasilnya negatif yaitu- 0,72 yang berarti korelasi antara interprofesional dan burnout perawat tidak searah.

Tabel 1

Interprosessional Colaboration (IPC) dan Burnout

\begin{tabular}{lccc}
\hline \multicolumn{1}{c}{ Indikator } & Rerata \pm SD & $\begin{array}{c}\text { Koefisien } \\
\text { korelasi }\end{array}$ & $\mathrm{p}$ \\
\hline $\begin{array}{l}\text { Interprofesional } \\
\text { Collaboration }\end{array}$ & $4,35 \pm 0,44$ & $-0,72$ & 0,62 \\
Burnout Perawat & $2,05 \pm 0,38$ & & \\
\hline
\end{tabular}

\section{PEMBAHASAN}

Pelaksanaan Interprofessional Collaboration di RS PKU Muhammadiyah Gamping dalam hal ini di unit keperawatan kritis yang meliputi IGD, ICU, dan ICCU dalam kategori baik dengan nilai mean 4,35. Bentuk pelaksanaan kolaborasi yang telah dilakukan oleh perawat di RS PKU Muhammadiyah Gamping meliputi aspek yaitu kemitraan, kerjasama, koordinasi dan pengambilan keputusan bersama. Beberapa aspek tersebut dilaksanakan dalam proses layanan kepada pasien yang tertuang dalam catatan perkembangan pasien terintegrasi (CPPT).

Kemitraan yang terjalin sesama perawat yang bekerja, memiliki kesamaan tujuan, saling memotivasi, terbuka dan saling jujur telah terbentuk dalam iklim kerja perawat di rumah sakit. Perawat secara terbuka mendiskusikan masing-masing tugas secara professional dan mempertimbangkan pendapat serta pandangan tim dalam proses rencana perawatan individu menggambarkan bahwa bentuk kerjasama antar tim atau antar tenaga keperawatan terbentuk dengan baik.

Interprofessional collaboration berpotensi menghasilkan beberapa manfaat dalam beberapa aspek, diantaranya pemahaman peran masing-masing tenaga professional, mengekspresikan pendapat anggota tim, memperbaiki hubungan atau komunikasi dengan pasien[3]. Suksesnya penerapan kolaborasi ini tergantung kepada bentuk komunikasi antar profesi yang ada [10]. Komunikasi dalam pelaksanaan IPC merupakan unsur yang sangat penting dalam proses pemberian asuhan kepada pasien dikarenakan kualitas asuhan yang diberikan meliputi kegiatan kolaborasi dari beberapa profesi kesehatan.

Beberapa profesi kesehatan yang ada di rumah sakit diharapkan memiliki kemampuan komunikasi yang baik, sehingga kolaborasi antar profesi kesehatan akan berfungsi secara efektif [11]. Permasalahan yang sering muncul dilingkungan kerja perawat adalah keterbatasan sumber daya manusia, jumlah pasien dan perawat yang tidak seimbang, kondisi tersebut akan berdampak pada keadaan psikis perawat seperti kelelahan, bosan, emosi dan perubahan mood yang akan menimbulkan stress pada perawat. Keadaan tersebut diharapkan dapat diminimalisir dengan pelaksanaan kerjasama antar tim kesehatan yang ada. 
Kebosanan kerja atau burnout pada perawat merupakan salah satu hal yang sering terjadi. Burnout perawat terdiri dari tiga dimensi yaitu kelelahan emosional, depersonalisasi dan rendahnya penghargaan diri. Hasil penelitian menunjukkan bahwa burnout perawat dalam kategori sedang. Perawat yang mengalami burnout dipengaruhi oleh berbagai faktor baik faktor internal maupun eksternal. Hal ini sesuai dengan pendapat [12] yang menyatakan bahwa burnout pada perawat dipengaruhi oleh faktor demografik (usia, jenis kelamin, pendidikan, lama bekerja dan pernikahan), faktor personal (stress kerja, beban kerja dan tipe kepribadian), dan faktor organisasi (kondisi kerja dan dukungan social).

Perawat yang mengalami burnout merasa dirinya lelah baik secara fisik maupun emosional, merasa tertekan, cemas dan tidak nyaman dalam bekerja. Hal ini sesuai dengan pendapat peneliti[13]bahwa perawat yang merasa kelelahan dalam bekerja cenderung akan mengalami stress dan burnout sehingga produktifitas dalam bekerja menurun. Kondisi saat ini yang terjadi pada perawat terutama perawat di ruang IGD, ICCU dan ICU adalah merasa lelah secara emosional karena perawat harus mengutamakan kepuasan pasien akan tetapi beresiko lebih tinggi terkena covid 19.

Kejenuhan kerja pada perawat juga dipengaruhi oleh faktor eksternal salah satunya yaitu faktor pimpinan. Dukungan yang baik dari pimpinan baik kepala ruang atau ketua tim akan meningkatkan motivasi dan penghargaan diri perawat sehingga kejadian burnout perawat menurun. Hal ini sejalan dengan pendapat penelian sebelumnya [14]yang menyatakan bahwa penerapan gaya kepemimpinan yang positif akan menekan kejadian burnout syndrome dan meningkatkan kinerja perawat.

Hasil analisis lebih lanjut bahwa gaya kepemimpinan transformasional sangat efektif dalam menurunkan angka kajadian burnout [15]. pada Kondisi pandemi COVID19 menuntut perawat untuk mengedepankan keselamatan pasien dan keselamatan diri sendiri sehingga dalam situasi saat ini peran pemimpin sangat penting untuk selalu memotivasi perawat agar semangat bekerja, membantu meminimalisir kecemasan, menjadi role model dalam menerapkan protokol kesehatan dan membantu tim perawat agar kebutuhan APD terpenuhi dengan baik sehingga perawat tidak mengalami burnout.

Dukungan sosial seperti rekan kerja dan interprofesional collaboration merupakan faktor yang berpengaruh dengan kejadian burnout perawat. Hasil penelitian yang dilakukan menunjukkan hasil yang berbeda yaitu interprofesional collaboration tidak ada hubungan dengan burnout perawat $(p>0,05)$ di RS PKU Muhammadiyah Gamping yaitu di ruang IGD, ICU dan ICCU. Hasil analisis peneliti bahwa perawat mengalami burnout karena dipengaruhi faktor-faktor lain seperti lingkungan kerja, beban kerja dan stres kerja.

Perawat akan mulai mengalami kejenuhan kerja jika merasa lingkungan kerjanya sedang tidak aman karena suatu hal yaitu karena situasi pandemic covid 19 sehingga perawat merasa cemas dan tidak aman karena mereka bekerja di unit kritis yaitu IGD, ICCU dan ICU yang resiko tertular covid 19 lebih tinggi. Hal ini sesuai dengan penelitian sebelumnya [16] yang menyatakan bahwa lingkungan kerja yang aman, nyaman dan kondusif merupakan salah satu faktor yang mempengaruhi burnout perawat.

Kondisi kerja yang menyenangkan membuat perawat merasa nyaman dan senang bekerja sehingga perawat tidak mengalami stress kerja. Hal ini sesuai dengan pendapat [11] yang menyatakan bahwa perawat tidak mengalami stress kerja jika berada pada situasi kerja yang menyenangkan. Perawat yang tidak stress dalam bekerja akan menikmati pekerjaannya, semangat dalam bekerja dan 
bisa menjalankan tugas dan tanggung jawabany dengan baik. Akan tetapi ada faktor lain yang mempengaruhi burnout pada perawat yaitu beban kerja.

Beban kerja yang dirasakan perawat juga memicu munculnya kejenuhan kerja sehingga akan menurunkan kinerja perawat. Hal ini didukung penelitian terdahulu [17] yang menyatakan bahwa beban kerja seperti banyaknya pasien yang masuk dalam satu hari, kondisi pasien atau tingkat ketergantungan pasien dapat memicu munculnya kebosanan kerja dan stress kerja perawat. Penelitian sebelumnya [18]juga menyebutkan bahwa beban kerja yang tinggidapat menyebabkan perawat mengalami kejenuhan dan kelelahan. Hal ini akan berdampak pada penurunan kualitas pelayanan yang diberikan perawat.

Analisis lebih lanjut dari peneliti bahwa interprofesional collaboration yang baik sangat dibutuhkan dalam meningkatan kinerja perawat tetapi bukan merupakan satu-satunya faktor yang dapat mempengaruhi perawat mengalami burnout. Perawat yang mengalami burnout perlu segera diatas agar tidak terjadi turnover perawat atau penurunan kinerja perawat yang dapat mempengaruhi kualitas asuhan keperawatan.

\section{SIMPULAN}

Hasil penelitian ini menunjukkan bahwa Interprofesional Collaboration dalam kategori tinggi, burnout perawat dalam kategori sedang dan tidak ada hubungan Interprofessional Collaboration dan burnout pada perawat. Limitasi penelitian ini hanya mengukur interprofessional collaboration dengan burnot pada perawat yang bekerja diunit perawatan kritis dan Gawat Darurat. Implikasi keperawatan dalam penelitian ini adalah untuk menurunkan burnout yang terjadi pada perawat dengan cara menekan beberapa hal yang dapat meminimalisir kejadian burnout tersebut. Selanjutnya, untuk mengetahui faktor yang sangat berperan dalam kejadian burnout ini dapat direkomendasikan untuk dapat diteliti oleh peneliti selanjutnya

\section{UCAPAN TERIMAKASIH}

Ucapan terimakasih kami sampaikan kepada Ristekdikti, LPPM Universitas 'Aisyiyah Yogyakarta atas fasilitas support yang telah diberikan kepada peneliti, RS PKU Muhammadiyah Gamping dan seluruh responden yang telah bersedia terlibat dalam penelitian ini.

\section{REFERENSI}

[1] RI K. Undang-Undang Republik Indonesia No. 36 tentang 2014 tentang tenaga kesehatan. Kementrian Kesehat RI 2014.

[2] Vellyana D. Analisis Budaya Keselamatan Pasien Dalam Pelayanan Kesehatan Di PKU Muhammadiyah Unit II Gamping. Universitas Muhammadiyah Yogyakarta, 2015.

[3] Gilbert JHV, Yan J, Hoffman SJ. A WHO report: Framework for action on interprofessional education and collaborative practice. J Allied Health 2010.

[4] Green BN, Johnson CD. Interprofessional collaboration in research, education, and clinical practice: working together for a better future. J Chiropr Educ 2015;29:1-10. https://doi.org/10.7899/jce-14-36.

[5] Kozier B, Berman S. Buku Ajar Fundamental Keperawatan: Konsep. 7th ed. Jakarta: EGC; 2010.

[6] Kasmarani M. Pengaruh beban kerja fisik dan mental terhadap stres kerja pada perawat di Instalasi Gawat Darurat (IGD) RSUD Cianjur. J Kesehat Masy Univ Diponegoro 2012;1:767-76.

[7] Sari IK. Faktor-faktor yang berhubungan dengan Burnout perawat di RSUD Haji Makasar. UIM Alaudin, 2015.

[8] Aftab N, Shah A, Mehmood R. Relationshipof self efficacy and burnout among physicians. Acad Res Int 2012;2:539-48.

[9] Fuada N, Wahyui I. Faktor-faktor yang berhubungan dengan stress kerja pada perawat kamar bedah Instalasi Bedah Sentral RSUD K.R.M.T. Wonsonegoro. J Kesehat Masy 2017;5:255-63.

[10] Setiadi AP, Wibowo Y, Herawati F, Irawati S, Setiawan E, Presley B, et al. Factors 
contributing to interprofessional collaboration in Indonesian health centres: A focus group study. J Interprofessional Educ Pract 2017;8:69-74. https://doi.org/10.1016/j.xjep.2017.06.002.

[11] Surtini S, Berlian YS. Hubungan Kondisi Kerja dengan Stres Kerja Perawat di Rumah Sakit. Fundam Manag Nurs J 2020;3:1-7.

[12] Patel B. The organisational factors that affect burnout in nurses. RCN Educ. Conf., West Middlesex University Hospital: 2014.

[13] Xie Z, Wang A, Chen B. Nurse burnout and its association with occupational stress in a cross-sectional study in Shanghai. J Adv Nurs 2011;67:1537-46.

https://doi.org/10.1111/j.13652648.2010.05576.x.

[14] Due MB, Nursalam N, Setiya Wahyudi A. Hubungan Gaya Kepemimpinan dengan Burnout Syndrome dan Kinerja Perawat di Ruang Rawat Inap RSUD Bajawa. Fundam
Manag Nurs J 2020;3:1-14. https://doi.org/10.20473/fmnj.v3i1.17800.

[15] Puspitasari NW, Sulisno M, Dwiantoro L, Kristina TN, Hartiti T. Penerapan Kepemimpinan Transformasional dalam Menurunkan Burnout Perawat Pelaksana. J Smart Keperawatan 2019;6:98-105. https://doi.org/10.34310/jskp.v6i2.289.

[16] Eliyana. Faktor-faktor yang Berhubungan dengan Burnout Perawat Pelaksana di Ruang Rawat Inap RSJ Provinsi Kalimantan Barat Tahun 2015. Arsi 2016;2:172-82.

[17] Sari NLPDY. Hubungan Beban Kerja Terhadap Burnout Syndrome Pada Perawat Pelaksana di Ruang Intermediet RSUP Sanglah. J Dunia Kedokt 2014;5:87-92.

[18] Nursalam. Manajemen Keperawatan Aplikasi Dalam Praktik Keperawatan Profesional Edisi 4. 4th ed. Jakarta: Salemba Medika; 2014. 